\title{
Immunohistochemical Comparison of Malignancy Between Radial Invasion and Mucosal Extension in Hilar Cholangiocarcinoma
}

\author{
KENICHI YOSHIDA ${ }^{1}$, RYUSEI MATSUYAMA ${ }^{1}$, RYUTARO MORI ${ }^{1}$, TAKAFUMI KUMAMOTO ${ }^{1}$, \\ KENICHI MATSUO ${ }^{1}$, KAZUHISA TAKEDA ${ }^{1}$, MITSUTAKA SUGITA ${ }^{1}$, YOSHIRO FUJII ${ }^{2}$, \\ KUNIYA TANAKA ${ }^{1}$, HIROSHI SHIMADA ${ }^{1}$ and ITARU ENDO ${ }^{1}$ \\ ${ }^{1}$ Department of Gastroenterological Surgery, Yokohama City University Graduate School of Medicine, Yokohama, Japan; \\ ${ }^{2}$ Department of Hepato-Biliary-Pancreatic Surgery, Faculty of Medicine, University of Miyazaki, Miyazaki, Japan
}

\begin{abstract}
Aim: To compare the cells of mucosal extension $(M E)$ and radial invasion (RI) in hilar cholangiocarcinoma (HCCA) for optimal resection. Materials and Methods: Fortysix patients underwent surgery for HCCA between 1992 and 2004. Immunohistochemical expressions of p53, Ki-67, matrix metalloproteinase-7 (MMP7), mucin 1 (MUC1), and Ecadherin were assessed at five different sites of the tumour and compared between the recurrence and non-recurrence groups. Results: Expression of E-cadherin was significantly lower in RI cells than in ME cells, and that of MMP7 and MUC1 was significantly higher in RI cells than in ME cells. Ki-67 expression was higher in ME cells than in RI cells. During the 11-year follow-up, recurrence in patients with RO resection was associated with significantly lower E-cadherin, higher MMP7, and higher Ki-67 expression. Conclusion: Removal of as many RI cells as possible should be a priority in resection of HCCA, followed by removal of ME cells. E-Cadherin appears to be associated with recurrence of HCCA.
\end{abstract}

Tumour cells of hilar cholangiocarcinoma (HCCA) invade radially into surrounding organs [defined as radial invasion (RI)] and extend along the mucosa (defined as [mucosal extension (ME)] $(1,2)$. Patients with RI cells remaining at the surgical margin after resection have poorer outcomes than those with remaining ME cells (3-7).

In the present study, five different sites of the tumour and its adjacent tissues were selected based on the dysplasia-carcinoma

Correspondence to: Kenichi Yoshida, MD, Department of Gastroenterological Surgery, Yokohama City University Graduate School of Medicine, Yokohama 236-0004, Japan. Tel: +81 457872650, Fax: +81 457829161, e-mail: kenichi@rd5.so-net.ne.jp

Key Words: Hilar cholangiocarcinoma, Ki-67, MMP7, MUC1, Ecadherin, recurrence. sequence: the tumour cells of the centre; the tumour RI and ME cells; the cells of dysplasia; and the cells of normal mucosa. The degree of malignancy of these sites was evaluated using five basic immunohistochemical markers (p53, Ki-67, matrix metalloproteinase-7 (MMP7), mucin1 (MUC1), and E-cadherin), which have been reported to be associated with malignancy in pancreatobiliary cancer (8-21). The sites of ME that were longer than $2 \mathrm{~cm}$ were defined as superficial spread (SS) (5) and assessed separately because the cell behaviour might differ and the procedures for resection may need to be different from that for short ME. The associations of these markers with recurrence were also assessed over the 11-year follow-up.

\section{Patients and Methods}

Patients. The subjects of this study were 46 patients (33 men, 13 women) diagnosed as having HCCA who underwent bile duct resection with or without hepatectomy at the Department of Gastroenterological Surgery, Yokohama City University Hospital between July 1992 and September 2004. The surgical procedures were bile duct resection alone in five patients, hepatectomy with bile duct resection in 36 patients, pancreatoduodenectomy with bile duct resection in three, and hepatopancreatoduodenectomy in two. Fourteen patients underwent vascular resection. R0 resection was performed in 32 patients $(69.6 \%)$. R1 resection was performed in 14 patients $(30.4 \%)$, of whom three had ME at the margin, and 11 had RI at the margin. There was no significant bile leakage during surgery. Perioperative mortality occurred within 2 months in three patients. The subjects were classified according to the International Union Against Cancer pTNM classification (22). Resected specimens of the 46 patients were reviewed retrospectively, and the recurrence status of these patients was evaluated as of December 2014 (Table I). The study was approved by the Institutional Review Board of Yokohama City University Hospital (\# HI-31), and informed consent was obtained from all participants.

Specimens. The resected bile ducts were opened longitudinally from the distal margin to the proximal margin. The tumours were classified macroscopically as papillary, nodular, and flat type, and 
histologically as papillary with or without SS, nodular with or without SS, and flat type with or without SS (Figure 1A). The histological types of the tumours were classified as papillary, welldifferentiated, moderately differentiated, or poorly differentiated adenocarcinoma, and mucinous or adenosquamous carcinoma (Table I) $(23,24)$.

Examined sites. Five different sites of the tumour and adjacent tissues were selected based on the dysplasia-carcinoma sequence and were examined histologically using haematoxylin and eosin staining (Figure 1B). They were classified using a textbook definition (24).

The molecular mechanisms of cholangiocarcinoma development differ by anatomical location (proximal/distal bile duct) in the biliary tree (25). Distal cholangiocarcinomas and intrahepatic cholangiocarcinomas were excluded, focusing on perihilar cholangiocarcinomas.

Immunohistochemical staining for p53, Ki-67, MMP7, MUC1, and E-cadherin. Tissue specimens were fixed in $20 \%$ buffered formalin overnight after resection, embedded in paraffin, sliced into 3- $\mu \mathrm{m}-$ thick sections, and mounted on MAS-GP type A-coated glass slides (Matsunami Glass Ind., Ltd., Osaka, Japan). Immunohistochemical staining was performed by the avidin-biotin complex method on sections from each specimen. Endogenous peroxidase was blocked by incubating the sections in $0.03 \%$ hydrogen peroxidase in methanol at room temperature for $30 \mathrm{~min}$. After washing three times with phosphate-buffered saline (PBS), $\mathrm{pH} 7.2$, for 5 minutes, sections were blocked with $10 \%$ normal rabbit serum in PBS for 15 minutes at $37^{\circ} \mathrm{C}$. The blocking serum was decanted, and the different primary antibodies for p53 (clone DO-7, mouse monoclonal, diluted 1:100; Dako, Glostrup, Denmark), Ki-67 (MIB-1, mouse monoclonal, diluted 1:100; Dako), MMP7 (1417B2, mouse monoclonal, diluted 1:500; Kyowa Pharma Chemical Co., Ltd., Toyama, Japan), MUC1 (Ma695, mouse monoclonal, diluted 1:100; Leica Biosystems Newcastle Ltd, Newcastle Upon Tyne, UK), and E-cadherin (HECD-1, mouse monoclonal, diluted 1:100; Takara Bio Inc., Shiga, Japan) in PBS were applied, respectively. They were applied overnight at $4^{\circ} \mathrm{C}$ for $\mathrm{p} 53$, for 15 min at $37^{\circ} \mathrm{C}$ for $\mathrm{Ki}-67$ and $\mathrm{MUC} 1$, for 60 minutes at $37^{\circ} \mathrm{C}$ for MMP7, and overnight at $4^{\circ} \mathrm{C}$ for E-cadherin. After the slides were washed three times in PBS for 5 min, the Dako EnVision+ System (Dako) was used for labelling. After the final PBS rinse, tissue sections were treated with $0.06 \%$ diaminobenzidine (DAB) for 5 minutes, rinsed, counterstained with haematoxylin, dehydrated, cleared with xylene, and coverslipped.

Counting. Cells were considered positively stained when the following was observed: unequivocal diffuse brown nuclear staining for p53 and Ki-67 (8); cytoplasmic staining for MMP7 (9); and staining of the cytoplasm and luminal border for MUC1 (10). For E-cadherin, cells were considered negatively stained when membranous expression was markedly reduced compared to noncancerous bile ducts (11). The number of positively stained cells out of 300 cells at each of the five sites was counted for each markers and recorded as labelling indices, representing the percentage of positively stained cells at each of the sites for each stain. Within each of the five sites, the area that had a substantial number of positively stained cells was selected for counting and obtaining the labelling indices. When the number of cells eligible for assessment was insufficient, the labelling indices were calculated from the number of obtainable cells. When there was no significant immunohistochemical expressions of p53, Ki-67, MMP7, MUC1, and E-cadherin at any of the sites, they were considered as having no expression. Thus, the average indices of the five markers at each of the five sites of the 46 patients were obtained for each stain.

Statistics. Labelling indices are expressed as means \pm standard error. Statistical analysis was carried out with one-way analysis of variance and the Bonferroni method to compare average percentage scores (labelling indices) among each of the five sites and among each of the three macroscopic types, and with the Mann-Whitney $U$-test to compare average percentage scores between the groups with recurrence and non-recurrence. When the $p$-value was less than 0.05 , the difference was considered significant. All statistical analyses were performed using SPSS statistical software version 22.0 for Windows (IBM Corp., Armonk, NY, USA).

\section{Results}

Forty-six resected specimens from patients with HCCA were investigated. The histologic types of the tumours are shown in Table I. Of the 46 patients, 11 did not have eligible ME cells, and five did not have eligible cells of dysplasia histologically. The number of patients who did not have significant immunohistochemical expression of p53, Ki-67, MMP7, MUC1, and E-cadherin was 20, 1, 6, 5, and 1, respectively.

Average labelling indices at five sites. The results of the average labelling indices of p53, Ki-67, MMP7, MUC1, and E-cadherin at the different sites are summarized in Figure 2. There were significant differences between RI and ME in MMP7, MUC1, and E-cadherin, indicating the malignancy of RI. There were significant differences between RI and D in all p53, Ki-67, MMP7, MUC1, and E-cadherin. Significant difference between RI and C was seen in MMP7.

Average labelling indices at superficial spread. The average SS scores for p53, Ki-67, MMP7, MUC1 and E-cadherin were $8.4 \% \pm 5.6 \%, 46.6 \% \pm 12.4 \%, 10.2 \% \pm 5.5 \%, 17.9 \% \pm 6.3 \%$, and $51.6 \% \pm 10.6 \%$, respectively. Sato et al. classified intraepithelial neoplasms into two categories, biliary intraepithelial neoplasia-3 (BilIN-3) and intraepithelial spread (IES), and they advocated the importance of distinguishing these two categories (26). In this study, BilIN-3 was seen in 28 patients, and IES was seen in seven. The average scores for p53, Ki-67, MMP7, MUC1, and E-cadherin in BilIN-3 were $7.1 \% \pm 3.7 \%, 42.4 \% \pm 5.7 \%, 8.8 \% \pm 3.7 \%, 15.4 \% \pm 3.5 \%$, and $49.3 \% \pm 5.5 \%$, respectively, and the average scores for p53, Ki-67, MMP7, MUC1, and E-cadherin in IES were $15.3 \% \pm 6.3 \%, 47.3 \% \pm 9.7 \%, 9.0 \% \pm 5.1 \%, 24.2 \% \pm 10.2 \%$, and $34.6 \% \pm 12.9 \%$, respectively. The p53 score was higher in IES than BilIN-3, but there was no significant difference. 
a

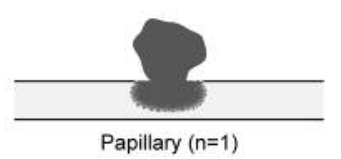

Papillary $(n=1)$

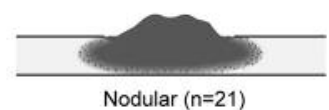

Nodular $(n=21)$

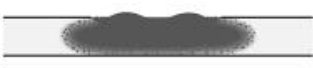

Flat $(n=17)$
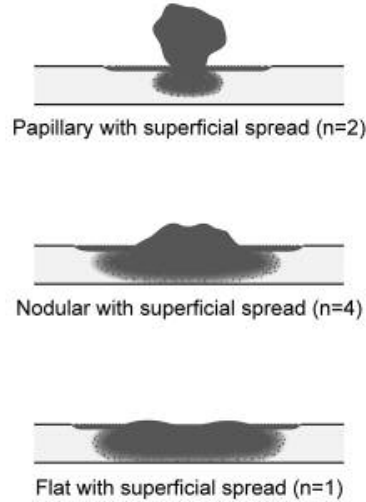

b
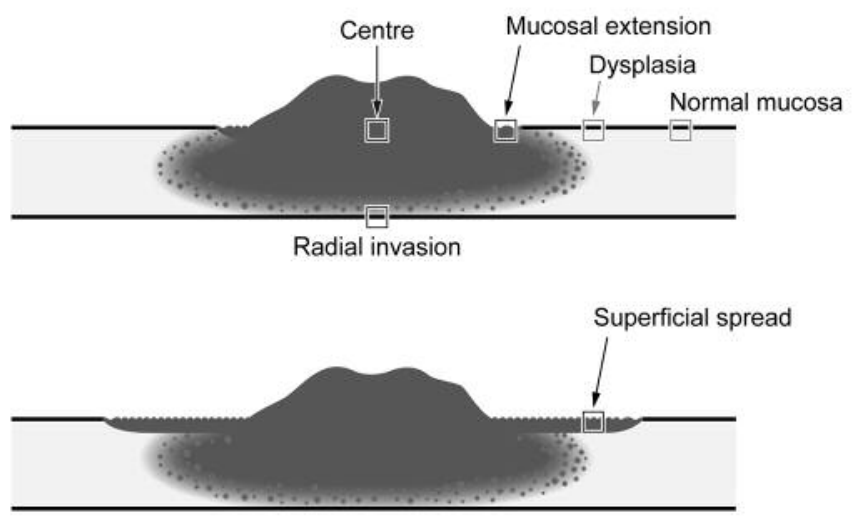

Figure 1. Classification of tumours. a: The tumours are classified as papillary with or without superficial spread, nodular with or without superficial spread, and flat type with or without superficial spread. b: Five different sites of the tumour and adjacent tissues were selected based on the dysplasia-carcinoma sequence and examined histologically using haematoxylin and eosin staining. Superficial spread was defined as long mucosal extension over $2 \mathrm{~cm}$.

Average marker scores in the recurrence and non-recurrence groups. Recurrence was found in 24 patients in the R0 resection group and 10 patients in the $\mathrm{R} 1$ resection group. Ten patients had remaining cancer cells at the RI site, and three patients had cancer cells remaining at the ME site (Table II).

There were associations between the markers and recurrence. After R0 resection, E-cadherin expression at RI sites was significantly lower in the recurrence group than in the no recurrence group ( $p=0.008)$, and expression of MMP7 and $\mathrm{Ki}-67$ at RI was significantly higher in the recurrence group than in the no recurrence group ( $p=0.04$ and $p=0.03$, respectively). Patients in the group with abdominal dissemination had significantly lower E-cadherin and higher MMP7 and Ki-67 expression at RI sites (Table III).

In the present study, p53, Ki-67, MUC1, E-cadherin, and MMP7 were not significantly associated with overall survival.

\section{Discussion}

ME/SS cells had high proliferative potential associated with high expression of Ki-67, but little invasive potential. RI cells had a higher degree of malignancy than ME/SS cells, demonstrated by reduced cell-cell adhesion associated with low expression of E-cadherin, invasive potential associated with high expression of MMP7, and strong malignancy associated with high expression of MUC1 and p53. The recurrence group had reduced expression of E-cadherin and high expression of MMP7 and Ki-67 at RI. Thus, RI cells should be resected first, followed by as many ME cells as possible.
The cells of the invasive front have been demonstrated to bear molecular changes associated with malignancy, such as high expression of membrane-type 1 (MT1)-MMP in breast cancer (27), MUC1 in colorectal cancer (28), ectopic laminin in gastric cancer (29), alpha smooth muscle actin in oral squamous cell carcinoma (30), and tumour-associated macrophages in HCCA (31). However, the biological difference between RI and ME in HCCA has not been sufficiently clarified.

The average E-cadherin score was significantly lower in $\mathrm{RI}$ cells than in ME cells $(12.5 \%$ vs. $46.4 \% ; p<0.001)$ in the present study. Reduced expression of E-cadherin has been reported to be associated with low survival, lymph node metastasis, high tumour stage, and strong blood vessel invasion in extrahepatic cholangiocarcinoma (12); it is an independent and significant prognostic factor along with N-cadherin and S100A4 (13), as well as an early event in tumourigenesis in both BilIN and intraductal papillary neoplasm of the bile duct (IPNB) lineages (14).

The average MMP7 scores were significantly higher in RI cells than in ME cells $(p<0.001)$. High MMP7 expression has been reported to be significantly associated with advanced TNM stage, especially with $\mathrm{T}$ and $\mathrm{N}$ factors, and perineural invasion, a poor prognostic factor (9). It as an independent and significant prognostic factor, along with intrahepatic metastasis (15), and is an indicator of invasive growth and poor outcome in cholangiocarcinoma (16).

The average MUC1 scores were significantly higher in RI cells than in ME cells $(p<0.001)$. High MUC1 expression is associated with poor survival in patients with 
Table I. Patient, tumour, and treatment characteristics ${ }^{\mathrm{a}}$.

\begin{tabular}{|c|c|c|}
\hline Characteristic & Category & Value \\
\hline Age, mean $\pm \mathrm{SD}$, years & & $65.4 \pm 9.1$ \\
\hline \multirow[t]{6}{*}{ Surgical procedure } & Bile duct resection & $5(10.9)$ \\
\hline & Hepatectomy + bile duct resection & $36(78.3)$ \\
\hline & Pancreatoduodenectomy + bile duct resection & $3(6.5)$ \\
\hline & Hepatopancreatoduodenectomy & $2(4.3)$ \\
\hline & Combined portal vein resection $b$ & $10(21.7)$ \\
\hline & Combined hepatic artery resection ${ }^{b}$ & $4(8.7)$ \\
\hline \multirow[t]{2}{*}{ Margin status } & 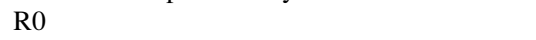 & $32(69.6)$ \\
\hline & $\mathrm{R} 1$ & $14(30.4)$ \\
\hline \multirow[t]{3}{*}{ Tumour remaining at } & Site of radial invasion & $11(78.6)$ \\
\hline & Site of mucosal extension & $3(21.4)$ \\
\hline & Site of superficial spread & $2(14.3)$ \\
\hline Perioperative mortality & & $3(6.5)$ \\
\hline Adjuvant chemotherapy & & $8(17.4)$ \\
\hline Adjuvant radiotherapy & & $34(73.9)$ \\
\hline \multirow[t]{9}{*}{ Recurrence ${ }^{c}$} & & $34(73.9)$ \\
\hline & Peritoneum ${ }^{\mathrm{d}}$ & $15(44.1)$ \\
\hline & Local recurrence ${ }^{\mathrm{d}}$ & $10(29.4)$ \\
\hline & Liver $^{d}$ & $3(8.8)$ \\
\hline & Lungd & $6(17.6)$ \\
\hline & Lymph node & $5(14.7)$ \\
\hline & Boned & $2(5.9)$ \\
\hline & Brain $^{\mathrm{d}}$ & $2(5.9)$ \\
\hline & PTCD $^{\text {de }}$ & $2(5.9)$ \\
\hline No recurrence & & $9(19.6)$ \\
\hline Tumour size, mean $\pm \mathrm{SD}, \mathrm{cm}$ & & $4.2 \pm 2.0$ \\
\hline \multirow[t]{4}{*}{ T Categoryf } & $\mathrm{T} 1$ & $0(0)$ \\
\hline & $\mathrm{T} 2$ & $29(63.0)$ \\
\hline & $\mathrm{T} 3$ & $9(19.6)$ \\
\hline & $\mathrm{T} 4$ & $8(17.4)$ \\
\hline \multirow[t]{2}{*}{ N Categoryf } & No & $25(54.3)$ \\
\hline & N1 & $21(45.7)$ \\
\hline \multirow[t]{2}{*}{ M Category ${ }^{\mathrm{f}}$} & M0 & $36(78.3)$ \\
\hline & M1g & $10(21.7)$ \\
\hline \multirow[t]{6}{*}{ UICC Stage } & I & $0(0)$ \\
\hline & II & $14(30.4)$ \\
\hline & IIIa & $4(8.7)$ \\
\hline & IIIb & $10(21.7)$ \\
\hline & IVa & $8(17.4)$ \\
\hline & $\mathrm{IVb}$ & $10(21.7)$ \\
\hline \multirow[t]{5}{*}{ Macroscopic type } & Papillary & $3(6.5)$ \\
\hline & Nodular & $25(54.3)$ \\
\hline & Flat & $18(39.1)$ \\
\hline & Tumour with mucosal extension & $35(76.1)$ \\
\hline & Tumour with superficial spreadh & $7(15.2)$ \\
\hline \multirow[t]{4}{*}{ Histological type } & Papillary adenocarcinoma & $2(30.4)$ \\
\hline & Well differentiated adenocarcinoma & $17(37.0)$ \\
\hline & Moderately differentiated adenocarcinoma & $19(41.3)$ \\
\hline & Adenosquamous carcinoma & $1(2.2)$ \\
\hline
\end{tabular}

SD: Standard deviation. aValues given are the numbers of patients (percentages) unless otherwise indicated. bembined with any of the above procedures. ${ }^{\mathrm{c} A s}$ of December 2014, defined clinically, based on histopathological or radiographic evidence. ${ }^{\mathrm{d}}$ Some data overlap for the type of recurrence. ${ }^{\mathrm{e}}$ The site where the percutaneous transhepatic cholangio drainage tube was inserted. ${ }^{\mathrm{f}} \mathrm{T}, \mathrm{N}$, and $\mathrm{M}$ categories were defined based on the histopathological evidence of cancer in the resected specimen. ${ }^{g}$ All were lymph node metastases proven in the resected specimen. h Superficial spread defined as long mucosal extension of over $2 \mathrm{~cm}$.

cholangiocarcinoma $(10,17)$, is predictive of overall survival along with fascin, epidermal growth factor receptor (EGFR), MUC4, and p27 in resected extrahepatic cholangiocarcinoma
(18), and is associated with poorer survival with the presence of tumour invasion and margin-positive resection in a study of resected IPNBs (19). 
a

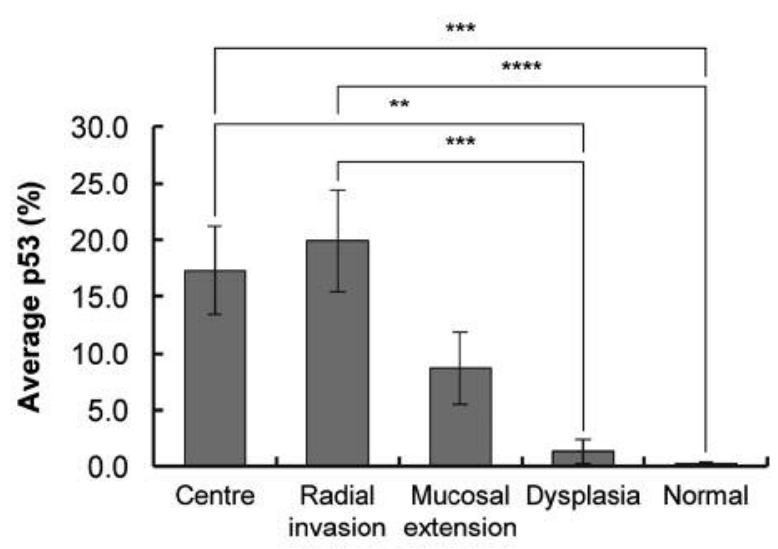

C

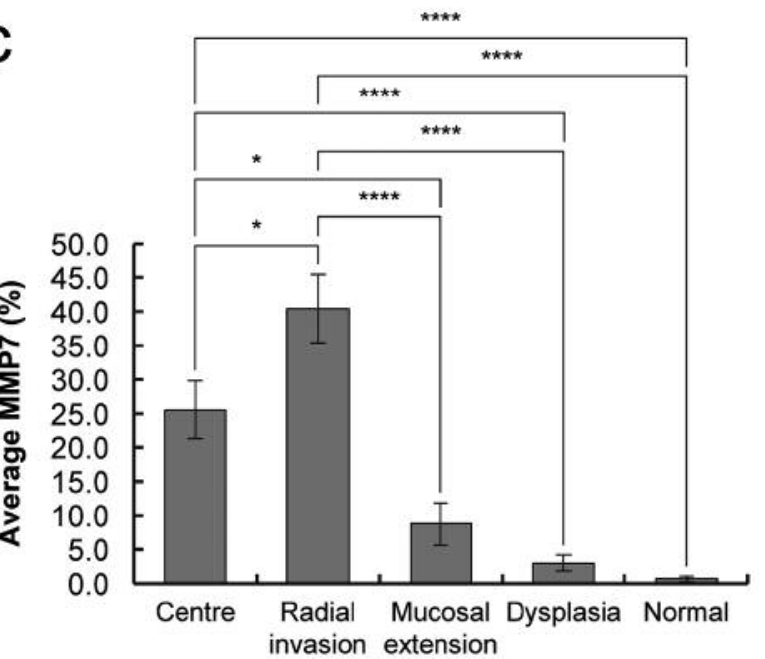

b

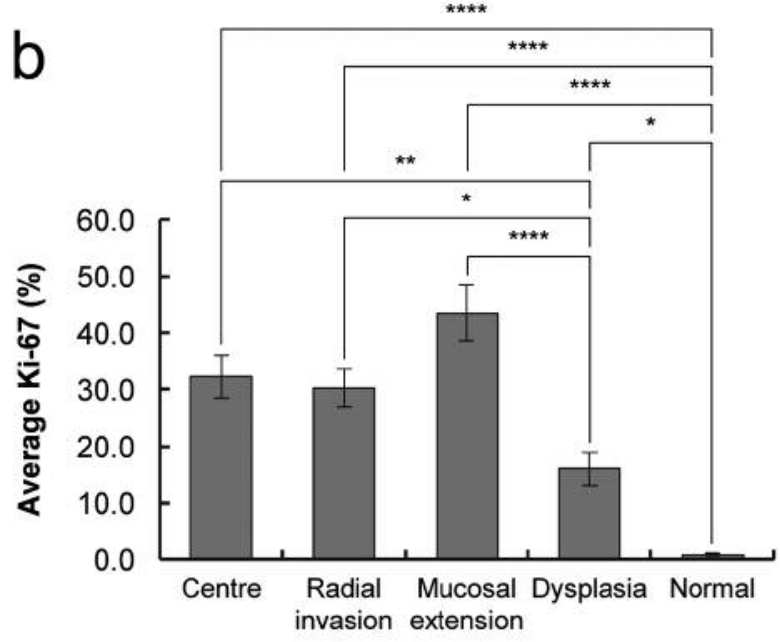

$\mathrm{d}$

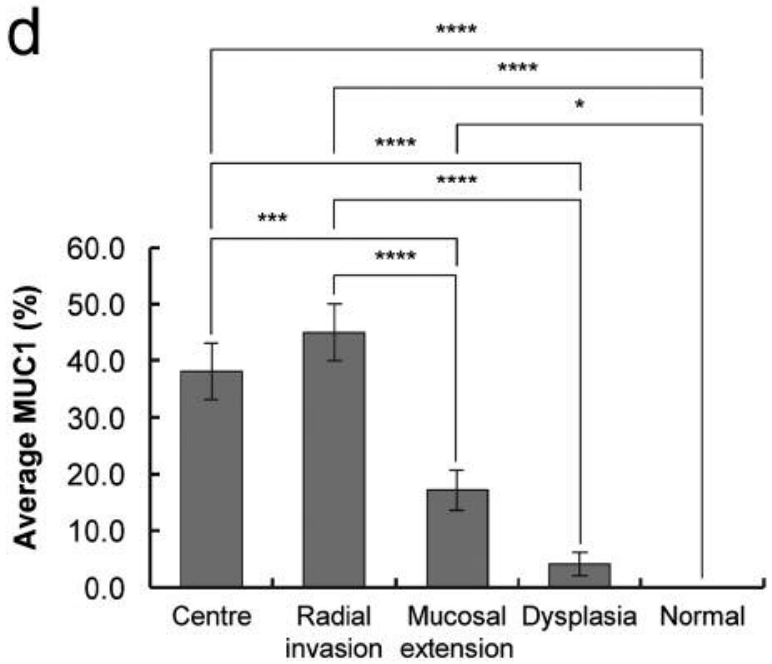

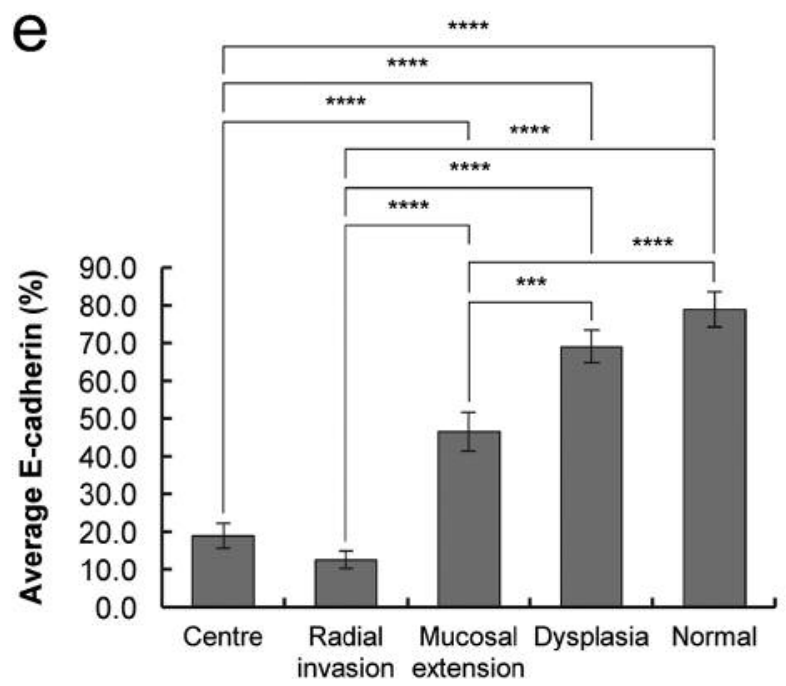

Figure 2. Labelling indices at the five sites for p53 (a), Ki-67 (b), matrix metalloproteinase-7 (MMP7) (c), mucin 1 (MUC1) (d), and E-cadherin (e). Data are the mean $\pm \operatorname{SEM}(n=46)$. Significantly different at $* p<0.05, * * p<0.01$, ***p $<0.005$, and $* * * p<0.001$. 
Table II. Curability and type of recurrence ${ }^{\mathrm{a}}$.

\begin{tabular}{|c|c|c|c|c|c|c|c|c|c|c|c|}
\hline & & \multicolumn{2}{|c|}{ Recurrence } & \multicolumn{8}{|c|}{ Site of recurrence ${ }^{b}$} \\
\hline & & No & Yes & Local & Peritoneum & Lung & Lymph node & Liver & Bone & Brain & PTCD \\
\hline R0 $(n=30)$ & No residual tumour & 6 & 24 & 5 & 11 & 3 & 3 & 3 & 1 & 2 & 1 \\
\hline \multirow[t]{3}{*}{$\mathrm{R} 1(\mathrm{n}=13)$} & Site of radial invasion ${ }^{\mathrm{c}}(\mathrm{n}=10)$ & 1 & 9 & 5 & 4 & 3 & 1 & & & & 1 \\
\hline & Site of mucosal extension $(n=3)$ & 2 & 1 & & & & 1 & & 1 & & \\
\hline & Site of superficial spreadd $(n=2)$ & 2 & & & & & & & & & \\
\hline
\end{tabular}

PTCD: Percutaneous transhepatic cholangio drainage. aPerioperative deaths excluded. bSome data overlap for the type of recurrence. ${ }^{c}$ Site where the PTCD tube was inserted. dSuperficial spread is defined as long mucosal extension of over $2 \mathrm{~cm}$.

Table III. Recurrence in patients with RO and R1 resection assessed by immunohistochemical staining $\mathrm{a}$.

\begin{tabular}{|c|c|c|c|c|c|c|c|c|}
\hline \multirow[b]{2}{*}{$\mathrm{R} 0$ resection } & & \multicolumn{2}{|c|}{ Recurrence } & \multicolumn{5}{|c|}{ Recurrence $^{b}$} \\
\hline & & No & Yes & Local & Peritoneum & Lung & Lymph node & Liver \\
\hline \multirow[t]{4}{*}{ RI } & & $(n=6)$ & $(n=24)$ & $(n=5)$ & $(n=11)$ & $(n=3)$ & $(n=3)$ & $(n=3)$ \\
\hline & E-Cadherin & $31.1 \pm 8.7^{\mathrm{cd}}$ & $8.3 \pm 2.3^{c}$ & $11.2 \pm 6.0$ & $5.0 \pm 2.4^{\mathrm{d}}$ & $17.5 \pm 8.5$ & $5.6 \pm 5.6$ & $10.2 \pm 6.0$ \\
\hline & MMP7 & $20.8 \pm 9.4^{\mathrm{ef}}$ & $55.2 \pm 6.9^{\mathrm{e}}$ & $53.0 \pm 10.2$ & $65.1 \pm 7.3^{\mathrm{f}}$ & $43.2 \pm 27.8$ & $64.4 \pm 32.2$ & $32.0 \pm 17.4$ \\
\hline & $\mathrm{Ki}-67$ & $15.0 \pm 6.5^{\mathrm{gh}}$ & $40.5 \pm 5.1 \mathrm{~g}$ & $50.9 \pm 11.1$ & $40.2 \pm 8.0^{\mathrm{h}}$ & $34.6 \pm 7.8$ & $27.7 \pm 13.9$ & $58.7 \pm 20.0$ \\
\hline $\mathrm{ME}$ & $\mathrm{Ki}-67$ & $\begin{array}{c}(\mathrm{n}=4) \\
15.0 \pm 8.8\end{array}$ & $\begin{array}{c}(n=18) \\
48.1 \pm 6.9\end{array}$ & $\begin{array}{c}(\mathrm{n}=4) \\
66.1 \pm 7.8\end{array}$ & $\begin{array}{c}(\mathrm{n}=8) \\
36.7 \pm 10.6\end{array}$ & $\begin{array}{c}(n=2) \\
61.7 \pm 23.3\end{array}$ & $\begin{array}{c}(n=2) \\
41.3 \pm 3.0\end{array}$ & \\
\hline \multicolumn{9}{|l|}{$\mathrm{R} 1$ resection } \\
\hline \multirow[t]{4}{*}{ RI } & & $(\mathrm{n}=3)$ & $(n=10)$ & $(n=5)$ & $(\mathrm{n}=4)$ & $(n=3)$ & $(n=2)$ & \\
\hline & E-Cadherin & $30.1 \pm 9.2^{\mathrm{i}}$ & $3.1 \pm 1.3^{\mathrm{i}}$ & $2.6 \pm 1.5$ & $5.4 \pm 3.0$ & $2.1 \pm 0.7$ & $1.7 \pm 1.7$ & \\
\hline & MMP7 & $15.0 \pm 5.0$ & $33.8 \pm 10.4$ & $37.4 \pm 17.3$ & $30.7 \pm 18.6$ & $18.8 \pm 12.3$ & $30.9 \pm 11.5$ & \\
\hline & $\mathrm{Ki}-67$ & $\begin{array}{c}18.7 \pm 8.3 \\
(\mathrm{n}=3)\end{array}$ & $\begin{array}{c}23.0 \pm 5.4 \\
(\mathrm{n}=7)\end{array}$ & $\begin{array}{c}33.4 \pm 7.3 \\
(\mathrm{n}=3)\end{array}$ & $\begin{array}{c}17.1 \pm 8.0 \\
(\mathrm{n}=3)\end{array}$ & $\begin{array}{c}10.6 \pm 2.7 \\
(\mathrm{n}=3)\end{array}$ & $\begin{array}{c}22.1 \pm 10.3 \\
(n=2)\end{array}$ & \\
\hline $\mathrm{ME}$ & $\mathrm{Ki}-67$ & $24.9 \pm 13.2$ & $55.2 \pm 9.1$ & $71.0 \pm 10.3$ & $61.7 \pm 1.1$ & $38.2 \pm 13.9$ & $48.3 \pm 8.3$ & \\
\hline
\end{tabular}

RI: Radial invasion; ME: mucosal extension. aValues given are the mean staining percentages \pm standard error. Perioperative deaths are excluded. bSome data overlap for the type of recurrence. Data with the same superscript letter differed significantly at $p<0.05$.

The average Ki-67 score in the present study was higher, although not significantly, in ME cells than in RI cells $\quad(p=0.12)$ (Figure 2B). High Ki-67 (MIB-1) expression in resected and biopsy specimens of cholangiocarcinoma has been associated with lymphatic invasion, obstruction of stent patency, and poor survival $(20,21)$ and is a useful predictor of lymph node metastasis (8). This suggests that ME cells do not always lack aggressiveness, but they may have strong proliferative potential associated with $\mathrm{Ki}-67$.

Clinically, many reports support resection of RI cells. Combined hepatectomy and resection of hilar vessels for en bloc resection of HCCA has now become standard. Portal vein resection has come to contribute to long-term survival in HCCA (32). However, hepatic artery resection has not yet been adequately justified $(33,34)$.
Cancer cells remaining at ME sites after resection of cholangiocarcinoma have been shown to be associated with late local recurrence $(3,7)$. We would consider that it is the high Ki-67 expression at ME sites that is associated with late recurrence, and that, as the present results suggest, ME where Ki-67 is highly expressed should be removed as much as possible considering the patient's status.

Recurrence was apparently associated with reduced Ecadherin expression and high MMP7 and Ki-67 expression at RI sites in the $\mathrm{R} 0$ resection group. The average E-cadherin score at RI sites was significantly lower in the recurrence than in the no recurrence group $(p=0.008)$. The average scores for MMP7 and Ki-67 at RI and those of Ki-67 at ME were higher in the recurrence group than in the no recurrence group ( $p=0.04, p=0.03$, and $p=0.053$, respectively). In the $\mathrm{R} 1$ resection group, E-cadherin expression was lower in the 
recurrence than in the no recurrence group. Reduced Ecadherin expression may be associated with strong malignancy and may be a cause of recurrence, especially abdominal dissemination, even after R0 resection. Ki-67 was highly expressed at both RI and ME in the recurrence group.

Long ME sites, or SS sites, were also assessed. They are occasionally found, and additional resection becomes necessary to accomplish R0 resection, but deciding the resection line may be difficult (35). The present results show that SS cells have almost the same immunohistochemical expression as ME. The average p53, Ki-67, MMP7, MUC1, and E-cadherin scores at SS sites were 8.4\%, 46.6\%, 10.2\%, $17.9 \%$, and $51.6 \%$, respectively. There were no significant differences between SS and ME sites in the expressions of these markers. The p53 score was higher at IES than at BilIN-3 ( $p=0.64)$, but there was no significant difference in the present study, consistent with Sato et al.'s report (26).

There are, however, some uncertain elements in this study. Staining does not actually show uniformly, and the labelling index is a semi-quantitative evaluation. To exclude irrelevant factors, unnecessary tissues were carefully excluded by haematoxylin and eosin staining, and evaluations were performed by several staff members. Postoperative therapies given were diverse, and HCCA recurrence was evaluated with long-term follow-up. Despite these difficulties, the difference in malignancy between RI and ME/SS has been clarified.

In conclusion, $\mathrm{ME}$ has high $\mathrm{Ki}-67$ expression, indicating proliferative potential. Removal of RI cells is a priority in cases where complete resection cannot be carried out in HCCA, and as many ME cells as possible should also be removed.

\section{Acknowledgements}

The Authors would like to thank Arata Ogihara for providing statistical support, Harumi Sakurada for providing technical support, and Yukari Nakamura for providing support.

\section{References}

1 Ito F, Cho CS, Rikkers LF and Weber SM: Hilar cholangiocarcinoma: current management. Ann Surg 250: 210-218, 2009.

2 Shimada H, Niimoto S, Matsuba A, Nakagawara G, Kobayashi $\mathrm{M}$ and Tsuchiya S: The infiltration of bile duct carcinoma along the bile duct wall. Int Surg 73: 87-90, 1988.

3 Wakai T, Shirai Y, Moroda T, Yokoyama N and Hatakeyama K: Impact of ductal resection margin status on long-term survival in patients undergoing resection for extrahepatic cholangiocarcinoma. Cancer 103: 1210-1216, 2005.

4 Sasaki R, Takeda Y, Funato O, Nitta H, Kawamura H, Uesugi N, Sugai T, Wakabayashi G and Ohkohchi N: Significance of ductal margin status in patients undergoing surgical resection for extrahepatic cholangiocarcinoma. World J Surg 31: 1788-1796, 2007.

5 Igami T, Nagino M, Oda K, Nishio H, Ebata T, Yokoyama Y and Shimoyama Y: Clinicopathologic study of cholangiocarcinoma with superficial spread. Ann Surg 249: 296-302, 2009.
6 Higuchi R, Ota T, Araida T, Kobayashi M, Furukawa T and Yamamoto M: Prognostic relevance of ductal margins in operative resection of bile duct cancer. Surgery 148: 7-14, 2010.

7 Nakanishi Y, Kondo S, Zen Y, Yonemori A, Kubota K, Kawakami H, Tanaka E, Hirano S, Itoh T and Nakanuma Y: Impact of residual in situ carcinoma on postoperative survival in 125 patients with extrahepatic bile duct carcinoma. J Hepatobiliary Pancreat Sci 17: 166-173, 2010.

8 Suto T, Sugai T, Nakamura S, Funato O, Nitta H, Sasaki R, Kanno S and Saito K: Assessment of the expression of p53, MIB-1 (Ki-67 antigen), and argyrophilic nucleolar organizer regions in carcinoma of the extrahepatic bile duct. Cancer 82 : 86-95, 1998.

9 Itatsu K, Zen Y, Yamaguchi J, Ohira S, Ishikawa A, Ikeda H, Sato Y, Harada K, Sasaki M, Sasaki M, Sakamoto H, Nagino M, Nimura Y, Ohta $\mathrm{T}$ and Nakanuma Y: Expression of matrix metalloproteinase 7 is an unfavorable postoperative prognostic factor in cholangiocarcinoma of the perihilar, hilar, and extrahepatic bile ducts. Hum Pathol 39: 710-719, 2008.

10 Park SY, Roh SJ, Kim YN, Kim SZ, Park HS, Jang KY, Chung MJ, Kang MJ, Lee DG and Moon WS: Expression of MUC1, MUC2, MUC5AC and MUC6 in cholangiocarcinoma: prognostic impact. Oncol Rep 22: 649-657, 2009.

11 Ashida K, Terada T, Kitamura Y and Kaibara N: Expression of E-cadherin, alpha-catenin, beta-catenin, and CD44 (standard and variant isoforms) in human cholangiocarcinoma: an immunohistochemical study. Hepatology 27: 974-982, 1998.

12 Araki K, Shimura T, Suzuki H, Tsutsumi S, Wada W, Yajima T, Kobayahi T, Kubo $\mathrm{N}$ and Kuwano $\mathrm{H}$ : E/N-cadherin switch mediates cancer progression via TGF- $\beta$-induced epithelial-tomesenchymal transition in extrahepatic cholangiocarcinoma. $\mathrm{Br}$ J Cancer 105: 1885-1893, 2011.

13 Nitta T, Mitsuhashi T, Hatanaka Y, Miyamoto M, Oba K, Tsuchikawa T, Suzuki Y, Hatanaka KC, Hirano S and Matsuno Y: Prognostic significance of epithelial-mesenchymal transitionrelated markers in extrahepatic cholangiocarcinoma: comprehensive immunohistochemical study using a tissue microarray. Br J Cancer 111: 1363-1372, 2014.

14 Itatsu K, Zen Y, Ohira S, Ishikawa A, Sato Y, Harada K, Ikeda H, Sasaki M, Nimura Y and Nakanuma Y: Immunohistochemical analysis of the progression of flat and papillary preneoplastic lesions in intrahepatic cholangiocarcinogenesis in hepatolithiasis. Liver Int 27: 1174-1184, 2007.

15 Hirashita T, Iwashita Y, Ohta M, Komori Y, Eguchi H, Yada K and Kitano S: Expression of matrix metalloproteinase-7 is an unfavorable prognostic factor in intrahepatic cholangiocarcinoma. J Gastrointest Surg 16: 842-848, 2012.

16 Miwa S, Miyagawa S, Soeda J and Kawasaki S: Matrix metalloproteinase-7 expression and biologic aggressiveness of cholangiocellular carcinoma. Cancer 94: 428-434, 2002.

17 Higashi M, Yonezawa S, Ho JJ, Tanaka S, Irimura T, Kim YS and Sato E: Expression of MUC1 and MUC2 mucin antigens in intrahepatic bile duct tumors: its relationship with a new morphological classification of cholangiocarcinoma. Hepatology 30: 1347-1355, 1999.

18 Ruys AT, Groot Koerkamp B, Wiggers JK, Klümpen HJ, ten Kate FJ and van Gulik TM: Prognostic biomarkers in patients with resected cholangiocarcinoma: a systematic review and meta-analysis. Ann Surg Oncol 21: 487-500, 2014. 
19 Rocha FG, Lee H, Katabi N, DeMatteo RP, Fong Y, D'Angelica MI, Allen PJ, Klimstra DS and Jarnagin WR: Intraductal papillary neoplasm of the bile duct: a biliary equivalent to intraductal papillary mucinous neoplasm of the pancreas? Hepatology 56: 1352-1360, 2012.

20 Murakami M, Sasaki T, Kuwada Y, Yamasaki S, Kuwahara K and Chayama K: Prognostic value of p53 and Ki-67 expression in resected or biopsy specimens of bile duct carcinoma. Oncol Rep 10: 1091-1096, 2003.

21 Rijken AM, Umezawa A, van Gulik TM, Bosma A, Polak MM, Offerhaus GJ, Obertop H and Gouma DJ: Prognostic value of cell proliferation (Ki-67 antigen) and nuclear DNA content in clinically resectable, distal bile duct carcinoma. Ann Surg Oncol 5: 699-705, 1998

22 Sobin L, Gospodarowicz $M$ and Wittekind C: TNM Classification of Malignant Tumours. Seventh Edition. New York, Wiley, 2009.

23 Albores-Saavedra J and Menck HR, Scoazec JC, Soehendra N, Wittekind C, Sriram PVJ and Sripa B: Carcinoma of the gallbladder and extrahepatic bile ducts. In: World Health Organization Classification of Tumours, Pathology \& Genetics, Tumour of the Digestive System. Hamilton SR and Aaltonen LA (eds.). Lyon, IARC Press, pp. 206-214, 2000.

24 Albores-Saavedra J and Henson DE and Klimstra DS: Tumors of the gallbladder, extrahepatic bile ducts, and ampulla of Vater. In: Atlas of Tumor Pathology, 3rd Series, fascicle 27. Rosai J and Sobin HL (eds.). Washington DC, Armed Forces Institute of Pathology, pp. 191-215, 1998.

25 Jarnagin WR, Klimstra DS, Hezel M, Gonen M, Fong Y, Roggin K, Cymes K, DeMatteo RP, D'Angelica M, Blumgart LH and Singh B: Differential cell cycle-regulatory protein expression in biliary tract adenocarcinoma: correlation with anatomic site, pathologic variables, and clinical outcome. J Clin Oncol 24: 1152-1160, 2006.

26 Sato Y, Harada K, Sasaki M and Nakanuma Y: Histological characteristics of biliary intraepithelial neoplasia-3 and intraepithelial spread of cholangiocarcinoma. Virchows Arch 462: 421-427, 2013.

27 Lodillinsky C, Infante E, Guichard A, Chaligné R, Fuhrmann L, Cyrta J, Irondelle M, Lagoutte E, Vacher S, Bonsang-Kitzis H and Glukhova M, Reyal F, Bièche I, Vincent-Salomon A and Chavrier P: p63/MT1-MMP axis is required for in situ to invasive transition in basal-like breast cancer. Oncogene 35 : 344-357, 2016.

28 Baldus SE, Mönig SP, Huxel S, Landsberg S, Hanisch FG, Engelmann K, Schneider PM, Thiele J, Hölscher AH and Dienes HP: MUC1 and nuclear beta-catenin are coexpressed at the invasion front of colorectal carcinomas and are both correlated with tumor prognosis. Clin Cancer Res 10: 2790-2796, 2004.
29 Caldeira J, Figueiredo J, Brás-Pereira C and Carneiro P, Moreira AM, Pinto MT, Relvas JB, Carneiro F, Barbosa M, Casares F, Janody F and Seruca R: E-cadherin-defective gastric cancer cells depend on Laminin to survive and invade. Hum Mol Genet 24: 5891-5900, 2015.

30 Dhanda J, Triantafyllou A, Liloglou T, Kalirai H, Lloyd B, Hanlon R, Shaw RJ, Sibson DR and Risk JM: SERPINE1 and SMA expression at the invasive front predict extracapsular spread and survival in oral squamous cell carcinoma. $\mathrm{Br} \mathbf{J}$ Cancer 111: 2114-2121, 2014.

31 Atanasov G, Hau HM, Dietel C, Benzing C, Krenzien F, Brandl A, Wiltberger G, Matia I, Prager I, Schierle K, Robson SC, Reutzel-Selke A and Pratschke J, Schmelzle M and Jonas S: Prognostic significance of macrophage invasion in hilar cholangiocarcinoma. BMC Cancer 15: 790, 2015.

32 de Jong MC, Marques H, Clary BM, Bauer TW, Marsh JW, Ribero D, Majno P, Hatzaras I, Walters DM, Barbas AS, Mega R, Schulick RD, Choti MA, Geller DA, Barroso E, Mentha G, Capussotti L and Pawlik TM: The impact of portal vein resection on outcomes for hilar cholangiocarcinoma: a multi-institutional analysis of 305 cases. Cancer 118: 4737-4747, 2012.

33 Miyazaki M, Kato A, Ito H, Kimura F, Shimizu H, Ohtsuka M, Yoshidome H, Yoshitomi H, Furukawa $\mathrm{K}$ and Nozawa S: Combined vascular resection in operative resection for hilar cholangiocarcinoma: does it work or not? Surgery 141: 581-588, 2007.

34 Matsuyama R, Mori R, Ota Y, Homma Y, Kumamoto T, Takeda $\mathrm{K}$, Morioka D, Maegawa J and Endo I: Significance of vascular resection and reconstruction in surgery for hilar cholangiocarcinoma: With special reference to hepatic arterial resection and reconstruction. Ann Surg Oncol 23: 475-484, 2016.

35 Endo I, House MG, Klimstra DS, Gönen M, D’Angelica M, Dematteo RP, Fong Y, Blumgart LH and Jarnagin WR: Clinical significance of intraoperative bile duct margin assessment for hilar cholangiocarcinoma. Ann Surg Oncol 15: 2104-2112, 2008.

Received July 26, 2017

Revised August 9, 2017

Accepted August 11, 2017 